\section{AUTORES APROXIMAM FAUNA BRASILEIRA DE CRIANÇAS}

O Brasil é um país megadiverso, uma das nações que detém maior biodiversidade do mundo, no entanto a fauna e a flora nativas são pouco conhecidas pela população brasileira. Um dos fatores que contribuem para esse cenário é a influência que a mídia exerce através de desenhos animados, filmes, jogos e livros infantis, nos quais o destaque são, frequentemente, os grandes mamíferos africanos. Esta é a principal razão pela qual uma criança de três anos reconhece o leão, a girafa e o elefante, ou ainda o panda, o urso e o lobo, mas dificilmente saberá quem é a anta, o lobo-guará, o peixe-boi ou o taman- duá. Nesse cenário, os livros infantis mostram-se um instrumento eficaz para auxiliar na comunicação, introduzir e apresentar, desde a infância, algo genuinamente brasileiro para, quem sabe, despertar para a importância de se preservar essas espécies. Essa é a aposta da ilustradora Laurabeatriz e do escritor Lalau, que desde 1994, dedicam-se a divulgar a fauna e a flora brasileira por meio da poesia. A ideia da coleção Brasileirinhos (2000), por exemplo, surgiu quando a dupla constatou que os animais brasileiros estavam criticamente ameaçados, com muitas espécies em vias de extinção-seja pela destruição

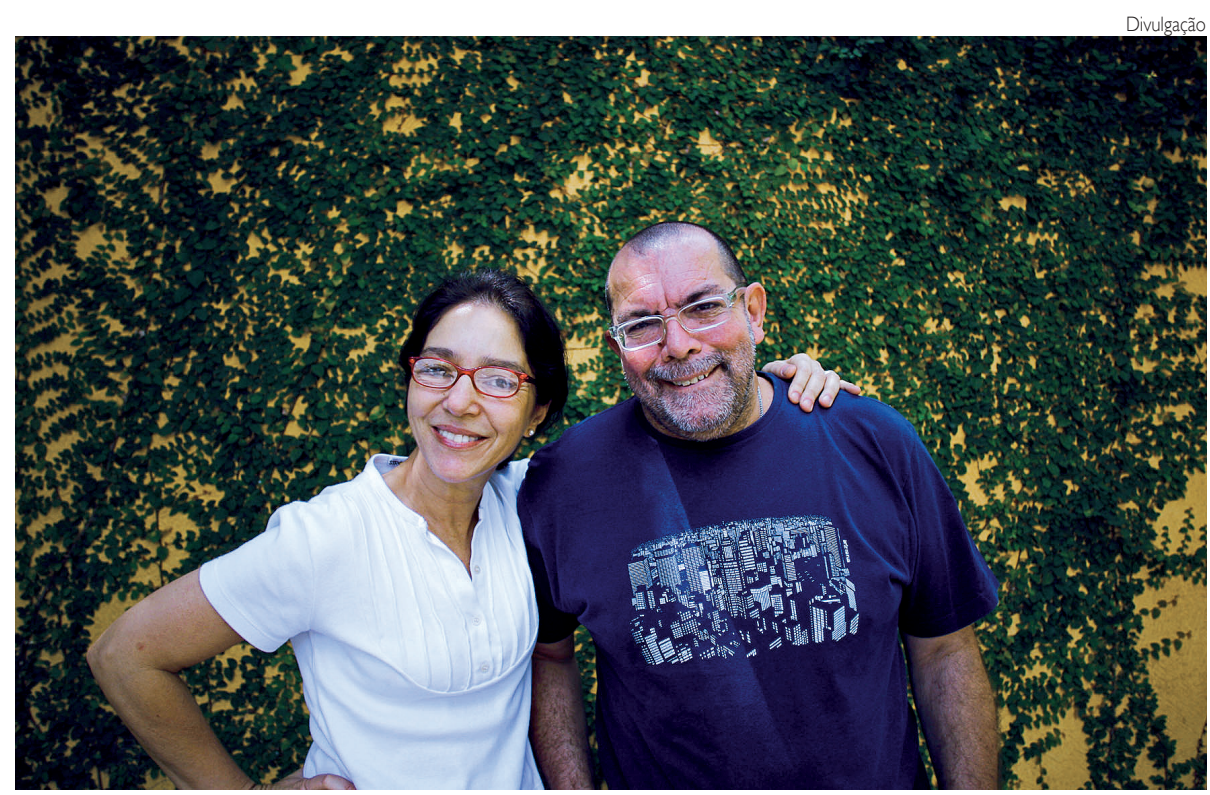

Laurabeatriz e Lalau. “Adorava andar no mato, na beira da represa, viajar com meu avô, meu pai e meus tios para o Pantanal. Acho que esse sentimento pela natureza, que tenho forte e arraigado dentro de mim, facilitou as coisas na hora de escrever", afirma Lalau

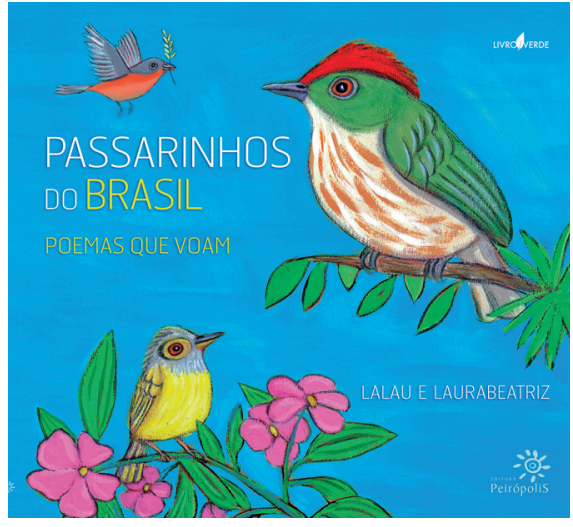

Capas de livros da dupla ressaltam a biodiversidade brasileira

do habitat ou pelo tráfico, e concomitantemente eles perceberam que as crianças brasileiras praticamente não conheciam a fauna nacional. $\mathrm{O}$ livro foi uma estratégia que nasceu com esse intuito, de mostrar para as crianças os animais ameaçados, afinal: "o público infantil de hoje é quem, no futuro, vai ajudar a preservar o nosso planeta".

Bem-te-vi e outras poesias (Cia das Letrinhas) foi o primeiro dos cerca de 40 títulos publicados pela dupla, dos quais destacam-se: Belezura marinha (2010), Boniteza silvestre (2007), a coleção Brasileirinhos, Árvores do Brasil (2011), Passarinhos do Brasil(2013), Diário de umpapagaio (2007) e Zum, zum, zum e outras poesias (2007). Hoje, chegando aos quase 20 anos de parceria, a criação é resultante de uma conversa em busca de temas diferentes, divertidos e que acrescentem coisas boas na vida de uma criança.

Contrariamente à percepção de que conceitos científicos ligados aos animais poderiam ser inapropriados ou entediantes para crianças, os autores buscam sempre "levar surpresa, 


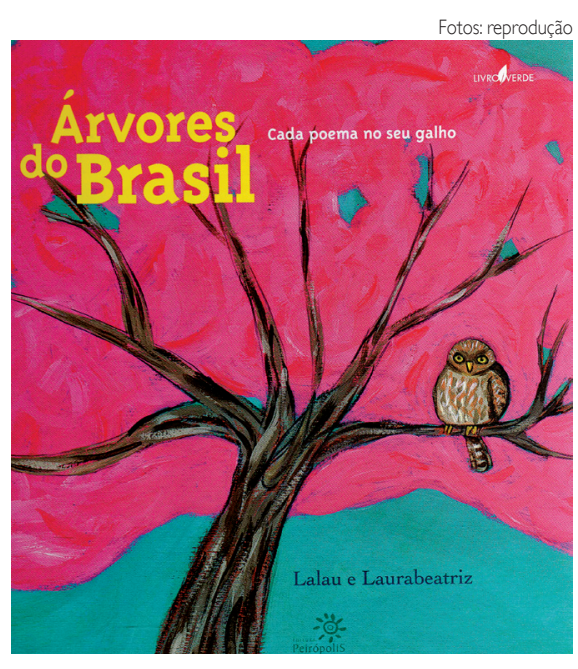

emoção, encantamento e, principalmente, diversão para os pequenos leitores. O lado científico fica por conta das informações que entram no conceito de criação dos livros".

Laurabeatriz e Lalau são otimistas em relação à mudança de comportamento de jovens. As visitas que realizam em escolas têm mostrado que a fauna está muito mais conhecida agora do que quando foi lançado o primeiro volume de Brasileirinhos no ano 2000. Os livros não são, no entanto, o único esforço empregado na mudança deste quadro. "É importante levar o assunto não só nos livros, mas também na sala de aula, em casa, na televisão, aplicativos, internet. Depois de incontáveis visitas a escolas, descobrimos que existe um ponto muito positivo nisso tudo: as crianças gostam de discutir, ouvir, descobrir coisas novas a respeito, e elas se envolvem, se emocionam, se mobilizam. Motivar, ainda mais, esse sentimento, onde for possível, é fundamental, produtivo e dá certo".

OUTRAS INICIATIVAS Outros autores vêm popularizando a fauna e a flo- ra brasileira através da literatura. Entre eles destacam-se a autora, bióloga e escritora brasiliense Nurit Bensusan com a obra Labirintos Parques Nacionais, premiada neste ano com o selo "O Melhor para a Criança", na categoria informativo, pela Fundação Nacional do Livro Infantil e Juvenil (FNLIJ) e o médico, entomólogo e escritor de livros infantis Ângelo Machado, comprometido e preocupado com a fauna e a divulgação dos conhecimentos científicos.

\section{Graziele Scalfi}

\section{MERCADO LITERÁRIO INFANTO-JUVENIL}

A expansão da classe média brasileira proporcionou um momento favorável para a indústria editorial. 0 número de livrarias aumentou cerca de $8 \%$ desde 2009 e os espaços voltados para as crianças estão mais sofisticados e aconchegantes. A venda de livros infantis ocupa o segundo lugar no ranking com $74 \%$ entre os tipos de livros comercializados pelas livrarias, de acordo com dados da Associação Nacional de livrarias (ANL). Os livros tradicionais competem com os livros-brinquedo interativos (popups, áudio etc), todos importados, em uma competição desleal que afeta, diretamente, o espaço dedicado aos nacionais.
HISTÓRIA E ARTE

\section{A São Paulo DO CINEMA: MODERNA E PÓS}

“São Paulo não pode parar”. A 24 fotogramas ou 30 frames por segundo, a maior cidade brasileira emergiu ese consolidou, ao longo do século XX, como a face mais genuína da modernidade nacional. Diferente do Rio de Janeiro - destacado por suas belezas naturais, sua Belle Époque e sua associação ao Ancién Regime - e embora destituída do modernismo "nato" de Brasília - a capital nacional projetada -, São Paulo é, até hoje, identificada como expressão máxima da modernidade do país. Modernidade, porém, conservadora e ambígua em diversos aspectos. Arte urbana por excelência, o cinema ganha seus primeiros impulsos no Rio e em São Paulo. Particularmente em São Paulo, a prosperidade econômica - baseada na exportação do café, expansão das ferrovias e industrialização da cidade - demanda registros cinematográficos cada vez mais frequentes, conforme se verifica na afluência do "cinema de cavação" (cineastas pagos para realizar filmes sob encomenda) a partir de 1916, dos primeiros cinejornais regulares e das primeiras companhias produtoras do país. Segundo Ismail Xavier em História e Documentário, (livro organizado por Eduardo Morettin, Marcos Napolitano e Mônica Kornis. São Paulo: FGV, 2012), filmes como Eletrificação da Com- 